\title{
Joaquim Cardozo: crítico literário
}

\author{
Joaquim Cardozo: literary critic
}

\section{Joaquim Cardozo: crítico literario}

\author{
(9) Elaine Cristina Cintra \\ Universidade Federal da Paraíba (UFPB), João Pessoa, Paraíba, Brasil. \\ E-mail: elcintra@yahoo.com
}

Resumo: Este trabalho objetiva discutir como a crítica literária do autor pernambucano Joaquim Cardozo formula um repertório de reflexões interessantes sobre a literatura de sua época, e como tais reflexões são significativas para um entendimento mais incisivo de sua singular obra poética.

Para isso, propõe-se aqui trazer alguns momentos desse pensamento crítico que se desenvolveu nas várias fases da vida do autor, os quais serão discutidos em uma perspectiva histórico-crítica a fim de se analisar as perspectivas que foram desenvolvidas por ele e como este recorte assinala uma visão da sua produção literária e da produção literária de seus contemporâneos.

Palavras-chave: Poesia brasileira moderna. Joaquim Cardozo. Crítica literária.

Abstract: This paper aims to discuss how the literary criticism of the author from Pernambuco Joaquim Cardozo formulates a repertoire of reflections on the literature of his time, and how such reflections are significant for a more incisive understanding of his unique poetic work. For this, it is proposed here to bring some moments of this critical thinking that has developed in the various phases of the author's life, which will be discussed in a historical perspective, in order to analyze the perspecti- 
ves that were developed and how this cut points to a vision of his literary production and his contemporaries.

Key-words: Modern brazilian poetry. Joaquim Cardozo. Literary criticism.

Resumen: Este trabajo objetiva discutir cómo la crítica literaria del autor pernambucano Joaquim Cardozo formula un repertorio de reflexiones interesantes sobre la literatura de su época, y como tales reflexiones son significativas para un entendimiento más incisivo de su singular obra poética.

Para ello, se propone aquí traer algunos momentos de este pensamiento crítico, que se desarrolló en las varias fases de la vida del autor, los cuales serán discutidos en una perspectiva histórica, a fin de analizar las perspectivas que fueron desarrolladas por él y como este recorte señala para una visión de su producción literaria y de sus contemporáneos.

Palabras clave: Poesia brasileña moderna. Joaquim Cardozo. Crítica literaria.

Submetido em 4 de março de 2019

Aceito em 16 de setembro de 2019.

Publicado em 23 de março de 2020 
“É preciso ler muito!", assim Joaquim Cardozo encerra uma entrevista em 1972, poucos anos antes de sua morte, concedida ao também poeta Alberto Cunha Melo. "É preciso ler muito" talvez seja precisamente a clave basilar que permeia toda sua significativa obra poética. Obra que dialoga com as poéticas vanguardistas ao mesmo tempo que anota em registros densamente líricos sua terra, transcendendo tanto uma verve quanto outra em uma dicção única na poesia brasileira; dicção esta que, diga-se de passagem, foi plenamente reconhecida como de excelência pelos grandes poetas, seus contemporâneos, como Manuel Bandeira, Carlos Drummond de Andrade e João Cabral de Melo Neto.

Cardozo foi um leitor assíduo de poetas e escritores de várias nacionalidades. Fluente em doze línguas, teve contato com os poetas modernos europeus pelas revistas que assinava e os livros que comprava e discutia em seu grupo. Dos autores dessa época, alguns diálogos foram mais reiterados pela crítica cardoziana, como, por exemplo, a influência baudelairiana que ressoa fortemente em sua poesia de Recife, como Moema D'Andrea (1998) ressaltou em seu trabalho, especialmente no que tange a este olhar diante da modernização, apreendida em seus poemas por um viés melancólico e saturnino. Por outro lado, Everardo Norões, responsável pela organização da reunião da obra do autor pelas editoras Nova Aguilar e Massangana em 2007, percebe na poesia citadina do autor, em que "tous les chemins vont vers la ville" ("todos os caminhos dão na cidade", epígrafe de "As alvarengas", primeiro poema publicado do autor), a influência de Émile Verhaeren, o Walt Whitman belga. E Drummond, no prefácio que fez ao primeiro livro do autor, em 1947, acentua como um de seus traços específicos um intelectualismo à Válery, modulando na crítica deste o pressuposto de que Cardozo apresentaria uma poesia com um rigor matemático em sua construção, o que se perpetuou na crítica cardoziana'. Não menos importante é a persistente melancolia pessoana que ressoa em sua lírica, expressão de um ser em estado de volubilidade,

1 Essa perspectiva crítica da poética de Cardozo pode ser vista no prefácio de Drummond ao livro Poemas (1947): “Espectador sensível da máquina do universo, o que o interessa é, por fim, um resultado intelectual." (DRUMMOND apud CARDOZO, 2007, p. 39). 
consciente de sua instabilidade, e que ainda não foi devidamente registrada no âmbito crítico.

O fato é que nos idos da década de 1920 em Recife, Joaquim Cardozo era a figura central no grupo de artistas e intelectuais que foram denominados como "Cenáculo do Lafaiete", pois se reuniam no Café Continental, na esquina da Rua Lafaiete em Recife, e que foram responsáveis por algumas das participações mais interessantes na cultura pernambucana da época. Nessas reuniões boêmias, das quais participavam artistas de diversas orientações estéticas e intelectuais que se voltavam para as questões sociais e políticas da época, discutia-se os rumos que a cultura brasileira vinha tomando e a presença de Cardozo era notadamente impactante, como se pode notar no testemunho que o desenhista e escritor Luís Jardim concedeu a Souza Barros: "Ali discutíamos, falávamos de tudo. Cardozo lia tudo, e novidade literária e artística da Europa ele conhecia através de revistas e livros - incansável leitor de tudo que sempre foi". (JARDIM apud BARROS, 1972, p. 161). ${ }^{2}$ É nesse ambiente cultural que Joaquim Cardozo começa a publicar seus primeiros poemas, especialmente na Revista do Norte, periódico em que ele colaborava e que representou um importante veículo para os direcionamentos artísticos do Cenáculo do Lafaiete.

A literatura cardoziana, porém, iria além da publicação de poemas em jornais e revistas, mas se consolidaria definitivamente na publicação do livro Poemas, obra que reuniu seus poemas e que foi organizada por seus amigos em 1947, quando o autor completou 50 anos. A ironia que circunda a publicação desse primeiro livro do autor se encontra no fato de que Manuel Bandeira o havia considerado um "poeta bissexto" em antologia organizada no ano anterior. Cardozo, entretanto, já apresentava na época uma obra fecunda, que incluiria também uma importante obra teatral; alguns contos de caráter regionalista e autobiográfico; uma profícua produção de crítica de arte, que abrange textos sobre artes plásticas (gravuras, pinturas, esculturas, salões nacionais e internacionais, escolas de arte), sobre tapeçaria, cultura e arquitetura e urba-

2 Segundo informação de Souza Barros (1972), o Cenáculo da Lafaiete vai do ano de 1923 até 1938, quando Cardozo se transfere para o Rio de Janeiro. 
nismo - nestes estão incluídos dois textos sobre Oscar Niemeyer, seu principal parceiro nas atividades de engenharia.

Ao todo foram reunidos na edição da Nova Aguilar 41 textos críticos, o primeiro publicado em 1925 e o último que foi uma publicação póstuma em 1983 (o autor faleceu em 1978). No entanto, tendo em vista que somente recentemente um acervo do autor foi organizado pela UFPE ${ }^{3}$, e ainda não se encontra totalmente catalogado, é possível aventar a hipótese de que há ainda vários outros textos a serem cotejados.

Sobre os escritos do autor voltados especificamente para a crítica e o estudo da literatura, pode-se dizer que eles estão dispersos em revistas e publicações jornalísticas, apesar de ainda não haver uma pesquisa mais ampla sobre o assunto. Há, também, alguns textos memorialísticos nos quais o autor revisa determinados momentos de sua trajetória de vida e de produção intelectual e artística que acenam para alguns pressupostos sobre as ideias de Cardozo a respeito da construção poética. Este trabalho objetiva, então, discutir como os textos críticos de Cardozo, especialmente aqueles que foram reunidos na edição Nova Aguilar/Massangana, formulam um repertório de reflexões interessantes sobre a literatura de sua época e como essas reflexões são significativas para um entendimento mais incisivo de sua singular obra poética.

Para isso, propõe-se aqui apresentar alguns momentos desse pensamento crítico, que se desenvolveu em fases distintas da vida do autor, a partir de uma perspectiva histórico-crítica, a fim de se analisar as perspectivas que foram desenvolvidas por ele e como esse recorte assinala uma visão de sua produção literária e de seus contemporâneos.

30 acervo de Joaquim Cardozo encontra-se atualmente no Memorial Denis Bernardes, na Biblioteca Central da Universidade Federal de Pernambuco, onde o autor atuou como professor na Escola de Engenharia. 


\section{O crítico e seu tempo}

A atividade crítica de Joaquim Cardozo inicia-se em 1925 e no âmbito da literatura, no Livro do Nordeste, edição comemorativa do $1^{\circ}$ centenário do Diário de Pernambuco, periódico em que trabaIhou como cartunista na década de 20. Na ocasião, o poeta ainda jovem publica o ensaio intitulado "Um poeta pernambucano: Manuel Bandeira". Seu texto foi precedido por uma nota de Gilberto Freyre que apresentava Joaquim Cardozo da seguinte forma: "É um estudo carinhosamente feito com simpatia e penetração. De uma viva sensitividade, é Joaquim Cardozo um dos poetas jovens mais interessantes de Pernambuco". (FREYRE apud CARDOZO, 2007, p. 499).

A crítica de Cardozo foi publicada na sequência do poema bandeiriano encomendado por Gilberto Freyre, "Evocação do Recife", que seria republicado em 1930 no livro Libertinagem. O jovem crítico Cardozo discute os três livros até então publicados por Bandeira, Cinza das horas, Carnaval e Ritmo dissoluto, destacando especialmente a tristeza de Bandeira: "comovedora melancolia, na tristeza deste homem doente, tristeza que impressiona, se aprende e se lastima à mais ligeira leitura de seus livros". (CARDOZO, 2007, p. 499, grifo meu).

Para Cardozo, Manuel Bandeira exporia em seus poemas uma "volúpia de ser triste, de uma satisfação prazente do sofrimento" (Idem, p. 505). Coincidência ou não, esse é um traço que será especialmente marcante na poética cardoziana, esta poética enevoada por um sentimento gritante de solidão e melancolia, destacado por José Guilherme Merquior (1996) em um importante estudo de Chão da crítica. ${ }^{4}$

Mais do que isso, Cardozo reitera o "individualismo" do poeta: "relevo pessoal numa criação simbólica". (CARDOZO, 2007, p. 505).

\footnotetext{
4 No artigo "Joaquim Cardozo, leitor de Bandeira", Éverton Barbosa Correia (2010), ao analisar a crítica de Cardozo a Bandeira, faz o seguinte comentário: Cinza das horas já é visto sob o escopo soturno de quem está esperando pela morte anunciada e a pique de acontecer; em Carnaval vemos um palhaço sombrio que ao invés de festejar a vida, esconde-se por trás de uma máscara cotidiana e sem remédio, que não encontra avesso e através do qual espelha os outros que se fantasiam no carnaval; O ritmo dissoluto concorre para a derrisão a que a vida está fadada e que já está inscrita nos objetos literários com que o poeta lida, seja um poeta parnasiano ou Camões. (CORREIA, 2010, p. 63).
} 
Bandeira portaria um estilo original e independente, que, mais do que apontar para o espírito de época, era irreconciliável com qualquer direcionamento que não fosse o mais íntimo. Da mesma forma, pode-se dizer que Cardozo se destaca pela pluralidade de sua poesia, que amalgama um estilo íntimo aos registros do espaço no qual se encontra, ao mesmo tempo em que é realizada por meio de um planejamento extremamente racional que o avizinha aos poetas intelectuais da estirpe cabralina.

A crítica foi bem recebida por Manuel Bandeira que, conforme Correia cita, escreve a Gilberto Freyre comentando a reação à leitura do texto de Cardozo: "O artigo do Cardozo... Aquele sacana me deixou o coração numa podreira. Me conte alguma coisa dele. É o mesmo de quem você fala no capítulo da pintura? [...] Mário de Andrade achou muito bom o estudo do Cardozo." (BANDEIRA apud CORREIA, 2010, p. 64).

Ainda hoje, essa primeira crítica parece fundamental aos estudos da poesia de Bandeira, marcando aspectos que incidiriam sobre livros posteriores do poeta de Pasárgada. Cardozo mostrou-se um crítico de poesia de agudíssima sensibilidade, prevendo, apesar do reduzido objeto, tendo em vista a grandeza quantitativa e qualitativa da futura obra poética de Bandeira, algumas linhas mestras de uma poesia marcada por uma dicção melancolicamente moderna. Ao jovem poeta pernambucano não lhe escapou essa impressão, e pode-se dizer que ele se irmanou a ela.

Ainda na década de 20, Cardozo publica uma resenha sobre o livro de Ronald de Carvalho, Toda a América, na qual destaca com especial ênfase as ilustrações do "estranho pintor De Garo": "fortíssimo pintor que deixou entre nós uma bem impressiva nota de seu valor com a expressão vitoriosa e altiva da sua grande arte pessoal" (2007, p. 507). O jovem poeta pernambucano ficara impressionado especialmente com a intensidade dos motivos sensoriais das ilustrações que acompanham os textos, especialmente a coloração "cheia de sol", com muitos verdes e vermelhos, que estampam uma claridade surpreendente. 
A plasticidade intensa também pode ser percebida em um dos fatores em que a poesia de Cardozo se destaca de maneira especial, a construção imagética, marcada por uma sensorialidade que se adensa em inusitadas construções frasais nas quais as funções adjetivas e substantivas se permutam de maneira bastante inusitada.

O texto sobre Ronald de Carvalho ainda traz um breve comentário sobre as claves artísticas desenvolvidas na época, aquilo que ele chama de "espírito moderno" e que se constituiria, a seu ver, na síntese de dois valores: a multidão e o inconsciente. Interessa perceber aqui o quanto Cardozo estava afinado com o pensamento baudelairiano e seus desdobramentos modernos, e como expressava conhecimento nesse momento das reflexões finisseculares sobre o inconsciente que permeariam a estética surrealista, lançada em 1924.

Para Cardozo, Ronald de Carvalho enfatizava nesse livro somente o primeiro termo, a multidão. É importante destacar que o próprio Cardozo foi um poeta que se dedicou a tal perspectiva e em sua obra encontra-se um valioso documento poético sobre Recife, focado especialmente na crítica à modernização abrupta da cidade na década de 20, que destruiu bairros e monumentos da tradição cultural da região. Os poemas "Recife morto", "Tarde no Recife", "Velhas ruas" são bons exemplos deste olhar nostálgico, que percebe o passado rondando fantasmagoricamente a cidade.

Cardozo, mais do que um poeta da cidade de Recife, é um crítico de arte que conclama a si mesmo esta posição. Em seu segundo exercício crítico, um ensaio de 1926 sobre a obra de Telles Júnior, importante pintor pernambucano conhecido por suas pinturas da paisagem pernambucana, especialmente do mar e dos coqueiros, Cardozo reclama-Ihe um olhar sobre a cidade e suas personagens, que registraria este momento recifense:

É até lamentável que, tendo uma tão grande preocupação de pintar o porto do Recife - o porto do Recife daquele tempo, antes das demolições e das avenidas novas, com os cais assombrados 
pelas gameleiras, ponto de reunião de vendedores ambulantes, de um pitoresco deliciosamente brasileiro e imperdoavelmente desprezado pelos artistas da época -, não tivesse ele penetrado mais intimamente na vida do porto de Recife, acompanhando os embarcadiços, os marinheiros que se refaziam da monotonia de bordo nos cafés e pequenos restaurantes dos arredores tão típicos, tão cheios de cor local e que seriam para nós, hoje, que já quase os não possuímos, uma doce alegria para os olhos, e seriam ainda uma análise dos caracteres estrangeiros em contato com a população quase toda mestiça de nossa gente pobre.

Parece mesmo, olhando-se as telas do porto do Recife, que o pintor é um estrangeiro e - aqui desaparece toda a significação regional de Teles - que olhou a cidade de longe, superficialmente - em verdadeiro contraste com as suas outras telas. (CARDOZO, 2007, p. 516).

Nos textos da década de 1920, Cardozo é um crítico de arte atento às orientações da Revista do Norte, periódico que tinha como proposta defender os aspectos culturais da região e que estava muito próximo do movimento regionalista encabeçado por Gilberto Freyre. Os primeiros poemas de Cardozo são marcados por essa direção e se voltam ao resgate dos elementos da tradição da cidade, como em "As alvarengas", primeiro poema publicado do autor que registra poeticamente a velha embarcação recifense, agora já sem uso na cidade modernizada. Outrossim, é nessa década que ele realiza as ilustrações e capa do primeiro livro do poeta Ascenso Ferreira, Catimbó, um marco do lirismo regionalista da época.

Tais manifestações levaram a crítica a obsessivamente destacar as questões regionais na poesia do autor que, longe de as negar, imbuía nas descrições locais uma dimensão mais ampla, como assinalou Antônio Houaiss, ao referir-se ao primeiro livro do poeta: 
Nos Poemas, há, de fato - como tributo de uma feição regionalista que vigorou em nossa poesia por volta de 1930 -, uma série de peças que têm como plano evidente a paisagem nordestina, pernambucana. Mas Joaquim Cardozo - que sofreu, naturalmente, a marca de nossa evolução poética e de suas conjunturas - se distingue no tratamento desse tema por lhe dar uma substância altamente evocativa e com larga projeção do seu subjetivismo no objeto poetizado, excluindo, ao mesmo tempo, o pitoresco e o exótico - tão explorado então -, que só aparecem episodicamente e em função do seu poder e necessidades evocativas - o que dá a esses já não o caráter do pitoresco e do exótico, mas o de elementos concretos para uma vivência poética autêntica e definida. (HOUAISS, 1976, p. 191 ).

Essa abordagem de Houaiss, na verdade, enceta um diálogo com o prefácio que Drummond escreveu para Poemas, no qual destacava como matriz da poética de Cardozo a paisagem de Recife:

\begin{abstract}
A província aparece a Joaquim Cardozo, nos idos de 1925, revestida daquela realidade pitoresca que se diria o único elemento, na massa das coisas, suscetível de interessar a visão modernista então vigente. Alvarengas, velhas ruas do Recife, suas pontes e edifícios públicos, igrejas de Olinda, chuva de inverno, mangue, cajueiros, engenhos, guerra holandesa - aí está um bom material para se fabricarem muitos poemas ao gosto da época, deliberadamente nacionalista e naturalista, em reação à fria impersonalidade de parnasianos helenizantes e mesmo à bruma flamenga de pós-simbolistas. (DRUMMOND apud CARDOZO, 2007, p. 35).
\end{abstract}

De fato, como aponta Houaiss, tentar relacionar as expressões de Recife e região em Cardozo a uma perspectiva programática do regionalismo nordestino impede o acesso às outras dimensões de seu exercício poético, como as questões filosóficas, históricas e existenciais que atravessam a subjetividade lírica do autor 
e que irão emoldurar poemas de extrema tensão e densidade, permeados de soluções formais que revigoram a tradição poética em figurações atentas às novidades vanguardistas. Como afirmou Merquior (1996), Cardozo seria um autor "entranhadamente moderno", a que acrescentaríamos "entranhadamente atento a seu tempo e local", o que se espelha também em seu exercício crítico.

\section{Poesia pura e simultaneísmo}

As décadas subsequentes, porém, trarão uma nova tonalidade às discussões literárias do autor. De 1930 a 1940, Joaquim Cardozo forma-se em engenharia, participa ativamente da criação da Diretoria de Arquitetura e Construção, a DAU, juntamente ao arquiteto Luiz Nunes, de inclinação moderna, e com o paisagista Roberto Burle Marx, com quem fará várias parcerias durante a vida. É também nesta década que Cardozo se torna catedrático dos cursos de Engenharia e Arquitetura, e é detido duas vezes por motivos políticos. Em 1939, após pronunciar um discurso polêmico, como paraninfo da turma de concluintes da Escola de Engenharia do Recife, é drasticamente demitido de seus cargos públicos. Em 1940 ele deixa Pernambuco e passa a residir no Rio de Janeiro, onde se estabelecerá, regressando a sua terra natal somente 30 anos depois.

A crítica literária do autor, nesse momento em que se dedica de maneira ostensiva à engenharia, especialmente com a profícua parceria com o arquiteto Oscar Niemeyer, ao mesmo tempo em que, por alguns anos, codirige a revista de arquitetura Módulo, é bastante parcimoniosa. Destaca-se um texto sobre o poeta Mateus de Lima, irmão de Jorge de Lima, publicado em 1934, que apresenta um olhar crítico diferenciado dos dois textos sobre literatura publicados na década anterior. Nesta crítica sobre o poema "Acalanto" desse autor, Cardozo discute as dificuldades de se exteriorizar o estado poético, em uma interessante abordagem da teoria e da recepção da poesia: 
Os homens possuem, todos, um campo infinito e mais ou menos contínuo de poesia, mas o que eles nem sempre conseguem é vencer a repugnância de revelá-lo; creio mesmo que a mais pura poesia não deve ser revelada, a revelação é uma impureza. Procurar exprimir, procurar um meio de transmitir a outrem um sentimento tão indefinido, tão impreciso, é tarefa a que por fim, geralmente, se chega insatisfeito porque não se pode atingir a beleza imaterial com o artifício grosseiro de certas convenções ou símbolos.

A leitura de um poema nem sempre traz ao leitor o verdadeiro estado emotivo do poeta, muitas vezes deturpado através de associações e decalques que ficam muito longe do seu mundo subjetivo. A leitura, sendo por si mesma um campo de emoções, pode até despertar na pessoa que lê uma estranha fonte de sensações interiores, como uma substância que se desprendesse das palavras escritas, frias e mortas.

O valor da poesia revelada dentro do limite das palavras é, na minha opinião, servir apenas de molde à poesia contínua e ilimitada dos leitores, e a boa ou má poesia está em bem ou mal satisfazer a esta finalidade.

Mateus de Lima, no seu poema "Acalanto", me ofereceu oportunidade de compreender que certos motivos exteriores, atualmente, ao nosso mundo emotivo surgem, às vezes, transfigurados em ritmos novos e perfeitos.

O motivo desse poema é o velho tema lírico e banal, explorado por artistas de quase todas as artes e que, por isso mesmo, já alcançou um grau tão alto de banalidade concreta que somente poetas puros como Mário de Andrade e Mateus de Lima poderiam tratá-lo, ou antes, torná-lo, ainda, um molde de emoções profundas. (CARDOZO, 2007, p. 518).

Observa-se nesse texto que a perspectiva crítica do autor está bastante voltada para a teorização do processo poético, revelando uma postura intelectualista que será bastante recorrente em seus textos críticos sobre artes plásticas e que demonstra o leitor obsessivo, vasto e diversificado que Cardozo era. 
Esta breve crítica deixa rastros não somente da posição valorativa do crítico Cardozo, que se coloca ante seu objeto de análise com um instrumental teórico, mas também da perfeita expressão de suas percepções e impressões diante do poema. Expressões como "o valor da poesia", "poetas puros", "estado emotivo" demonstram um leitor arguto e atento às questões que a crítica literária impôs em determinado momento aos pretensos poetas, e também uma escolha diante das sugestões da década. Em outras palavras, o crítico Cardozo sinaliza uma busca pela poesia como objeto artístico capaz de atingir a plenitude da expressão, distanciando-se de algumas práticas dessublimadoras recorrentes no início do século XX.

Nota-se, neste texto, que o autor se volta à reflexão sobre o que é o poético (um estado interior) e sua exteriorização no poema, e o modo como ele provoca, no leitor, as reminiscências de seu próprio estado poético. Tal posição lembra o modo como Valéry (1999) discorre sobre o efeito do poema no leitor, discutindo a inspiração como algo que impacta mais o leitor que o próprio produtor do texto poético. O leitor Cardozo refaz esse percurso alinhavando que o alto grau de expressividade poética da subjetividade lírica propicia um alto grau de estado poético do leitor. E uma vez mais, o crítico revela o poeta, pois é possível perceber na poética desse autor a tentativa de se apropriar de uma poeticidade extrema, de uma resolução absoluta do exercício poético no qual uma tensão imperiosa perpassa versos perfeitamente acabados, sem nenhum escape de dispersão, em que a precisão redunda em soluções poéticas únicas.

A década de 40 será o momento em que o autor receberá um maior reconhecimento público de sua obra poética. Em 1946, Manuel Bandeira o inclui em sua Antologia dos poetas brasileiros bissextos contemporâneos, o que o tornará conhecido nacionalmente. Em 1947, seus amigos, em homenagem aos seus 50 anos, lançam seu primeiro livro, Poemas, com prefácio de Carlos Drummond de Andrade e ilustrações de Luís Jardim. Em 1948, João Cabral de Melo Neto inclui poemas de Cardozo em sua Pequena antologia pernambucana, publicada sob o selo de "O livro inconsútil". Enfim, 
um quarto de século após a publicação de seu primeiro poema em revista, o poeta torna-se um autor publicado em livro que recebeu a atenção merecida dos principais autores e críticos da época.

A publicação de seu primeiro livro de poemas impulsiona Cardozo a novos projetos poéticos. É na década de 50 que o autor publica a primeira parte da trilogia Trivium, dando prosseguimento a sua produção poética. Além disso, esse é o momento em que sua atividade crítica se torna mais profícua. São publicados 24 textos críticos, sendo que quatro são de literatura: "O poeta Bertolt Brecht" (1956), "Teatro total" (1956), "Memorial do errante" (1956), "O poeta visual ou de livre leitura" (1957).

Dentre essas críticas, destaca-se a leitura que o autor faz do livro Memorial do errante, de Afonso Félix de Sousa. Nela, Cardozo chama a atenção para a alta potencialidade lírica de Sousa, marcada pelo uso de versos livres, ao mesmo tempo em que há uma volta para as molduras mais tradicionais do gênero, como a canção. Ao comentar o livro propriamente dito, o poeta pernambucano destaca que o autor abandonou as paisagens regionais e voltou-se para temas mais universais, e, na forma, adotou "o frêmito do simultâneo". (CARDOZO, 2007, p. 551). Uma vez mais, o autor se mostra atento aos direcionamentos estéticos de seu tempo.

O texto "O poema visual ou de livre leitura", de 1957, volta às suas reflexões sobre a simultaneidade no poema. Nesse texto, Cardozo, remetendo às experiências do concretismo naquele tempo em voga, reconhece que é necessário discutir o valor desse tipo de poema que extrapola a dualidade simultaneidade/temporalidade, características respectivamente das artes visuais e da literatura. Para isso, ele elabora várias sugestões de como os recursos sonoros (efeitos fonéticos, aglutinações, fragmentações, orações ramificadas, elisões, composição de palavras novas) deveriam ser usados no poema, o que levaria a uma perspectiva mais visual. É notável, assim, que a reflexão sobre uma poesia mais experimental tenha ocorrido concomitante à elaboração de poemas que poderiam ser lidos não como concretistas, mas como visuais, como em Trivium e na série "Caligramas". 
É também nesse texto que o autor sugere a criação do ISEP, Instituto Superior de Estudos Poéticos: "Ali se poderia estudar de maneira mais definitiva o problema do poema visual, e ainda as questões de intuitivismo poético e de metapoesia, esta última já tão bem insinuada no poema de João Cabral de Melo Neto 'Uma faca só lâmina"'. (CARDOZO, 2007, p. 555). Como se pode perceber, a atividade crítica do autor havia tomado um rumo mais teórico, sugerindo, inclusive, iniciativas institucionais para se direcionar os estudos literários.

\section{Pernambucanidade}

A partir da década de 1960, a crítica literária do autor se torna cada vez mais memorialística, íntima e confidencial, voltada para um balanço de sua obra e da obra de sua geração. Exceção a isso é o texto de 1968, "Dez poetas do nordeste", prefácio do livro Agenda poética do Recife, com apresentação e seleção de Cyl Gallindo. Cardozo apresenta os dez poetas buscando definir aquilo que chama de suas "pernambucanidades", que seria por ele assim definida: "Há em todos eles um poder, um ímpeto decisivo e generoso que, historicamente, sempre foram apanágio da gente dessa região, permanentemente iludida, deprimida e maltratada pelos poderes mais altos do país." (CARDOZO, 2007, p. 583). Esses poetas apresentariam uma "ânsia de saber, a curiosidade de contemplar o espetáculo do mundo do conhecimento", uma "coerência de valores estéticos" herdada de Manuel Bandeira e vista em Oliveira e Silva, Austro Costa, Eugênio Coimbra Júnior, Mauro Mota, João Cabral de Melo, até os mais jovens, Carlos Pena Filho, Audálio Alves, César Leal, Edmir Domingues, Tomaz Seixas, Gonçalves de Oliveira, Carlos Moreira e outros. Enfim, uma '"vontade de ser' autônoma no complexo cultural luso-brasileiro" (CARDOZO, 2007, p. 584), que implicaria em um medo da "inflação da cultura estrangeira". Completa-se o círculo. A mesma independência de espírito registrada 
na primeira crítica de Cardozo, ao falar de Bandeira, é, neste, que seria o último texto crítico propriamente dito do autor, definida como essência da pernambucanidade. Cardozo afasta-se assim, de vez, da alcunha de "regionalista", não no sentido mais banal que foi imposto aos autores do norte, ao afirmar em si e nos outros seus conterrâneos uma subjetividade singular que, de fato, inclui esses autores no rol dos poetas que se entranharam nas perplexidades de se estar no mundo e tornar esse estado em poesia e conhecimento.

O poeta, que se destacou por sua produção livre de qualquer posicionamento estético específico, independente, encontra nesse momento de maturidade, seus pares. Mas o que lhes agrega a ideia de grupo é justamente um espírito livre, independente, que seria herdado de sua terra natal.

\section{Referências bibliográficas}

BARROS, Souza. A década de 20 em Pernambuco (uma interpretação). Rio de Janeiro: Paralelo, 1972.

CARDOZO, Joaquim. Poesia completa e prosa. Organização e introdução geral Everardo Norões. Rio de Janeiro: Nova Aguilar; Recife: Fundação Joaquim Cardozo, Massangana, 2007. 720 p. (Biblioteca Luso-brasileira. Série brasileira).

CORREIA, Éverton. Guavira Letras: o texto poético, comparativismo, fontes primárias e outras semioses. Três Lagoas, Universidade Federal de Mato Grosso do Sul, n. 10, ago./dez. 2010. Disponível em: www.pgletras.ufms.br/revistaguavira. Acesso em: 20 out. 2018.

D'ANDREA, Moema. A cidade poética de Joaquim Cardozo (a elegia de uma modernidade). João Pessoa: Xerox, 1998. HOUAISS, Antônio. Drummond mais seis poetas e um problema. Rio de Janeiro: Imago, 1976. 
MERQUIOR, José Guilherme. Uma canção de Cardozo. Razão do poema. Rio de Janeiro: Topbooks, 1996. p. 17-35.

VALÉRY, Paul. Variedades. Organização e introdução João Alexandre Barbosa. Tradução Maiza Martins de Siqueira. Posfácio Aguinaldo Gonçalves. São Paulo: Iluminuras, 1999. 